\title{
NBSIR 74.619
}

\section{Measurement Methodology for Determining the Sound Output of Toy Guns}

Marilyn A. Cadoff and Donald S. Blomquist

Applied Acoustics Section

Mechanics Division

Institute for Basic Standards

National Bureau of Standards

Washington, D. C. 20234

August 1974

Final Report for Period $7 / 1 / 73-6 / 30 / 74$

Prepared for

Consumer Product Safety Commission

Bureau of Engineering Sciences

5401 Westbard Avenue

Bethesda, Maryland 20014 

NBSIR 74-619

\section{MEASUREMENT METHODOLOGY FOR DETERMINING THE SOUND OUTPUT OF TOY GUNS}

Marilyn A. Cadoff and Donald S. Blomquist

Applied Acoustics Section

Mechanics Division

Institute for Basic Standards

National Bureau of Standards

Washington. D. C. 20234

\section{August 1974}

Final Report for Period $7173-63074$

\section{Prepared for}

Consumer Product Safety Commission

Bureau of Engineering Sciences

5401 Westbard Avenue

Bethe sda, Maryland 20014

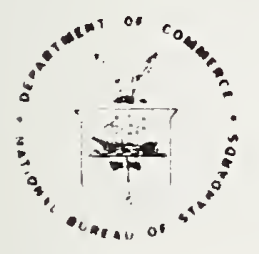

U. S. DEPARTMENT OF COMMERCE, Froderick B. Dent, Secretary 
. 


\section{Measurement Methodology for Determining the Sound Output of Toy Guns}

Marilyn A. Cadoff and Donald S. Blomquist

In recent years, a great concern has been expressed for consumer protection and safety, especially for children. As an outgrowth of this concern, acoustical testing of potentially-hazardous noise-producing toys has been carried out at the National Bureau of Standards for the Consumer Product Safety Commission under the authority of the Toy Safety Act of 1969. This report outlines a methodology which was developed to measure the noise levels of toy guns. In addition, the rationale and technical back-up for the methodology are discussed, and the regulations setting allowable noise levels for toy guns are given.

Key words: Children; consumer safety; guns; hearing damage; noise; standard apparatus; toys.

\section{Introduction}

Since March 1971, the Applied Acoustics Section of the National Bureau of Standards has conducted a program for, initially, the Bureau of Product Safety (Food and Drug Administration, U. S. Department of Health, Education, and Welfare) and, presently, the Consumer Product Safety Commission, to provide the following services:

1. identify noise-producing toys which are potentially hazardous to children's hearing and/or safety;

2. acquire data on selected toys on an as-requested basis; and

3. develop generic test methods by which noise exposure due to toys can be determined.

A method for testing all types of toy caps utilizing cap pistols to explode the caps [1] 1 / is presently in force. However, on the basis of data.obtained since the publication of this test method, a new procedure has been developed for testing paper caps [2], which are often sold as a separate unit from cap pistols. It is proposed that, for paper caps, this procedure replace the existing test method. In addition, sufficient data have been collected through the testing of toy rifles and other toy guns that it is now considered appropriate to propose a test method which will be broad enough to encompass all classes and types of toy guns.

The proposed measurement methodology is the subject of this report.

\section{Definitions}

For purposes of this report, the following definitions of terms are offered:

- cap: A small paper or plastic capsule containing an explosive material that discharges on impact.

- toy pistol: A replica of a gun which is made to be held and fired with one hand.

- toy rifle: A replica of a gun which is made to be fired from the shoulder.

- muzzle: The opening at the front end of the barrel of a gun.

- barrel: The straight tube of a gun, which directs the projectile.

$1 /$ Numbers in brackets refer to the literature references at the end of this report. 
stock: The wooden, metal, or plastic piece of a rifle which holds the barrel.

butt plate: The back surface of the stock of a rifle which rests against the shoulder of the operator.

impulsive noise: Brief excursions of sound pressure which significantly exceed (by $10 \mathrm{~dB}$ or more) the ambient environmental sound pressure. The duration of a single impulse is usually less than one second [3] .

continuous noise: On-going (steady-state) noise whose intensity remains at a measurable level (which may vary) without interruption over an indefinite period or a specified period of time [4].

3. Technica1 Back-Up

\subsection{Effects of Noise and Parties Affected}

It is important to identify the parties affected by toy gun noise and the nature of the effects. The operator of the toy as well as other persons close by are affected and the nature of the effects range from communication interference to possible hearing damage.

For this reason, the methodology developed is applicable to both the operator of the gun and to other persons in close proximity to the gun. In each case, two levels are determined. One is the peak impulsive sound level produced by the gun, and the other is the continuous noise emitted by the gun.

\subsection{Rationale for Methodology}

In general, toy guns other than those utilizing caps (which are typically sold separately) are purchased and used as a system. Thus, when it is at all possible, the toy gun and its associated noise-making device should be tested as a system. The situation with toy caps for guns is more complicated. There are some caps (e.g., plastic caps) which can only be exploded in a gun which has been specially designed for these caps. In such a case, the gun and caps should be tested as a unit. However, with the great majority of caps, they are sold separately from the gun and can be exploded by means other than a gun (e.g., hammer, rock). For this reason, and because it was noted during initial tests that there was a great deal of variation in the measurement results which seemed to be attributable to the type of cap pistol used to fire the caps, a method was developed to test paper caps without using a pistol.

It is not always possible to make a single noise measurement which would allow for an evaluation of the hazard presented by the firing of the gun to both the operator and a bystander. A determination should be made of the impulsive and continuous noise emission to ascertain the hazard presented to near-by-persons. In addition, for guns for which there is a well-defined operator location (a rifle as compared to a pistol), measurements are also needed to evaluate the impulsive and continuous noise emission at the approximate location of the operator's ear. The operator location is defined as being $6 \mathrm{~cm}$ directly above the butt plate of the rifle. For a pistol, where there is no welldefined operator position, the measurement location in the basic test configuration where the maximum sound level is produced will be used to judge the hazard presented to the operator of the gun. With these considerations in mind, a measurement configuration employing several test positions was developed which should provide an indication of the hazard presented by impulsive and continuous firing of a toy gun to both the bystander and the operator. The test configuration was designed with the assumption that the sound source of the gun is located at either the trigger or the muzzle, which is usually the case. However, provisions have been made in the methodology for those guns in which the sound source is located in the stock, or along the barrel between the muzzle and the trigger. 


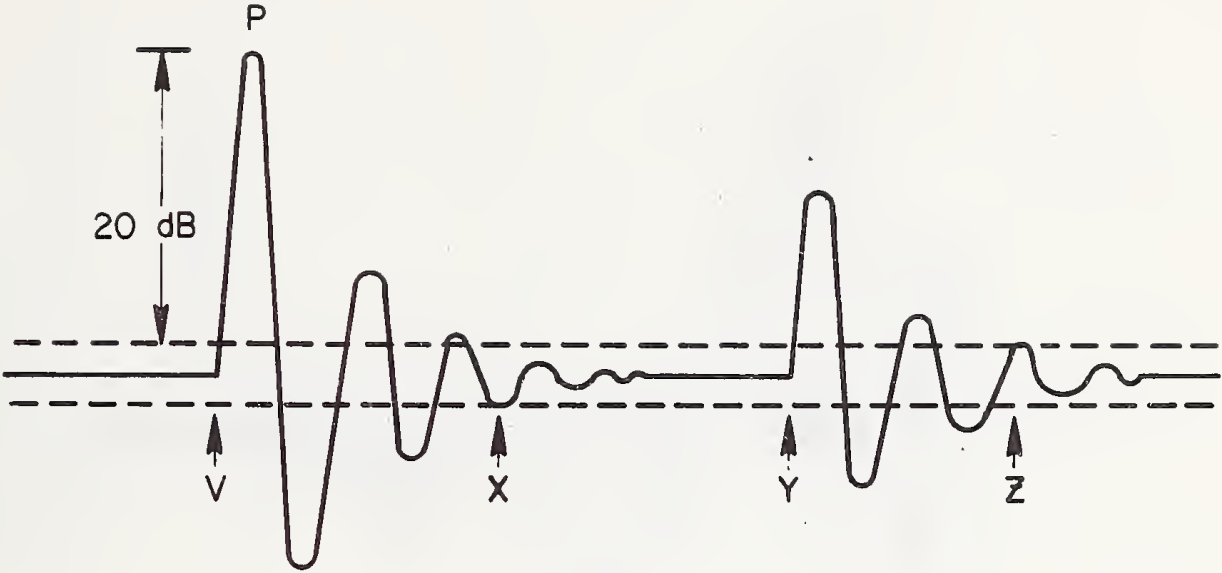

\section{TIME}

Figure 1a. Idealized waveform of impulse noise, from Ward, et a1 [5].

\subsection{Methodology Development}

The CHABA impulse-noise damage-risk criterion for gunfire [5] requires that, for each firing, three quantities be measured: the peak voltage, the A-duration, and the B-duration. Figures $1 \mathrm{a}$ and $2 \mathrm{a}$ illustrate the CHABA definitions of these quantities. In the figures, the peak voltage, $P$, is the highest instantaneous voltage level reached at any time by the impulse. The pressure-wave duration (A-duration) is the time required for the initial wave to reach the peak voltage level and return momentarily to the baseline (point $V$ to point $W$ in Figure 2a). The pressure-envelope duration (B-duration) is the total time that the envelope of the pressure fluctuations (positive and negative) is at 1 east $10 \%$ of the recorded positive peak pressure level; i.e., within $20 \mathrm{~dB}$ of the maximum amplitude. In Figure 1a, the $\mathrm{B}$-duration would be from $\mathrm{V}$ to $\mathrm{X}$, plus $\mathrm{Y}$ to $\mathrm{Z}$. In the tests of the toy caps, the measurements were made in accordance with the test method [1] mentioned earlier (reproduced in Appendix A), and the peak voltages were converted to peak sound pressure levels (in decibels relative to 20 micropascals) using the response to the calibrated measuring system. Figure lb presents a copy of an actual wave form produced by a toy cap. Most toy rifles present a different waveform than that shown in Figures $1 a$ and $1 b$ (see Figures $2 a$ and $2 b$ for examples). However, it is still possible to give values for the peak voltage and A- and B- durations. The current Federal regulation [6] governing the noise levels permitted by toy cap guns is based entirely on the peak sound pressure level. The B-duration of the guns was short enough that it was not thought to be a significant factor requiring regulation. The regulation presented in Section 4 is also based entirely on the peak level produced by the gun, but further experiments will be conducted to ascertain whether, for guns other than cap guns, the B-duration is significant and should be accounted for in the regulation. 


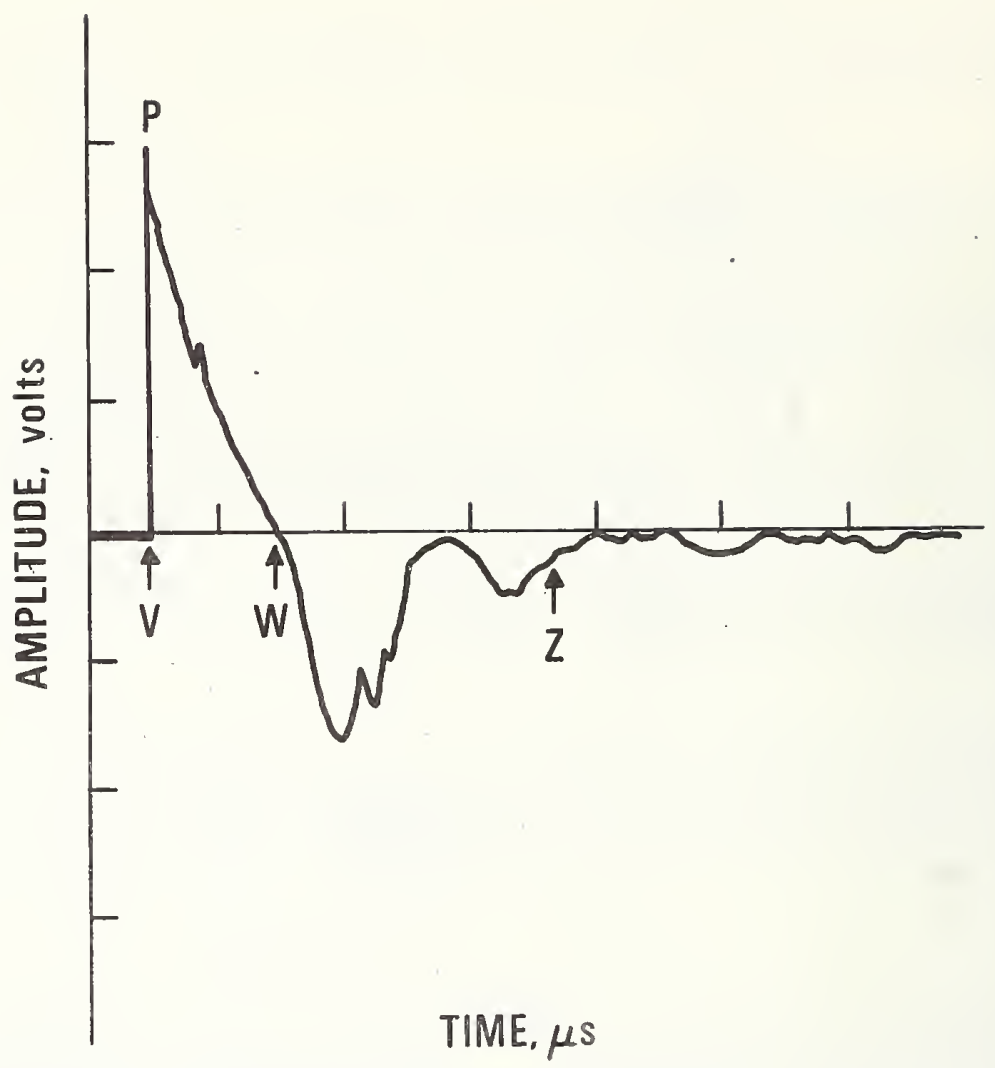

Figure 1b. Approximate waveform for toy caps/cap pistols. P represerts the peak voltage, point $\mathrm{V}$ to point $\mathrm{W}$ is the $\mathrm{A}$-duration, and point $\mathrm{V}$ to point $\mathrm{Z}$ the B-duration. Each division on the vertical axis represents 1 volt, and, on the horizontal axis, each division is 50 microseconds.

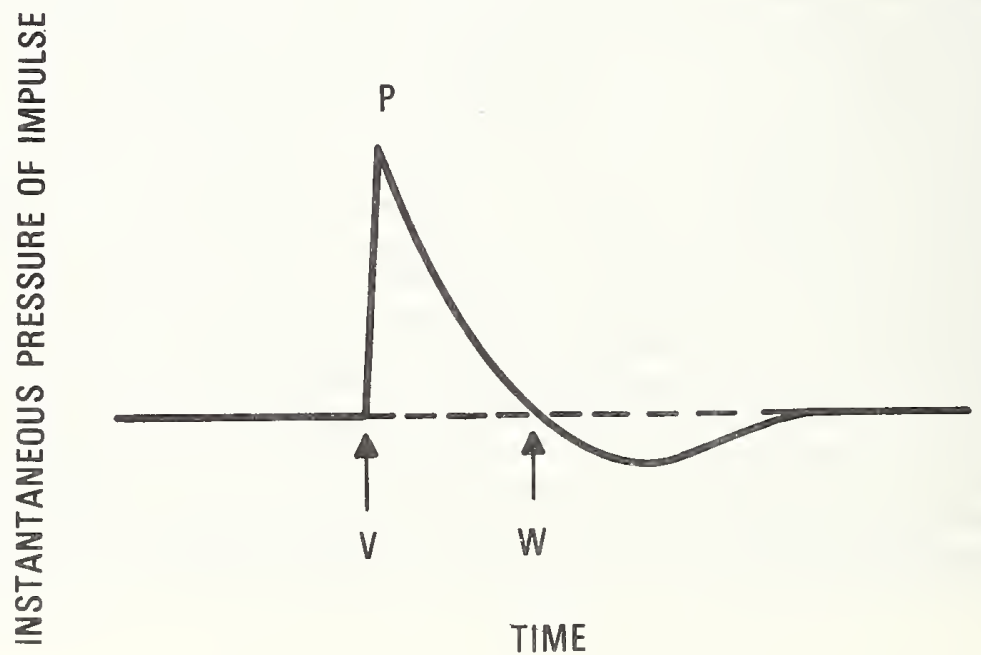

Figure 2a. Idealized waveform of another type of impulse noise from Ward, et al [5]. 


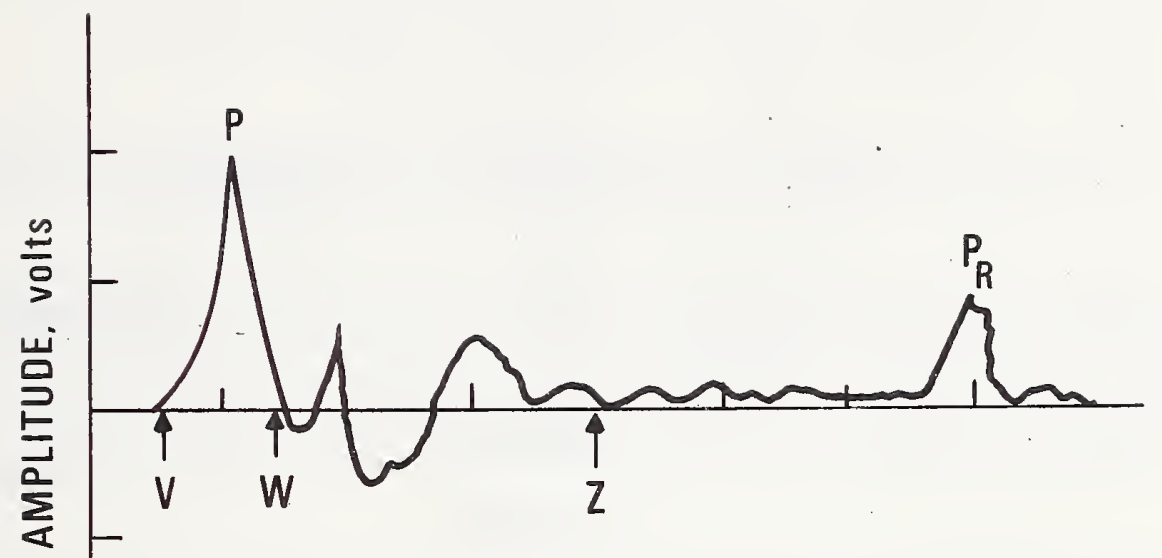

Figure 2b. Approximate waveform for toy rifles. P represents the peak voltage, point $\mathrm{V}$ to point $\mathrm{W}$ is the A-duration, and point $\mathrm{V}$ to point $\mathrm{Z}$ the B-duration. $\mathrm{P}_{\mathrm{R}}$ is the point at which the room reflections appear on the tracing. Each division on the vertical axis represents 1 volt, and, on the horizontal axis, each division is 1 millisecond.

At the present time, no measurement methodology exists for continuous noise-producing toy guns. However, over the past several years, sufficient data have been collected so that now it is considered appropriate to propose a test method for this class of toys. It was decided to use the A-weighted sound level as the indicator of the noise emission. There are several reasons for this. First, a measure was needed that would correlate well with the known effects of noise on the individual. The A-weighting network of a sound level meter is designed to respond to a sound in a manner similar to the human ear, discriminating heavily against low frequency components. Extensive research has shown it to be a reasonable, single number indicator of subjective response to noise [4,7]. Also, the A-weighted sound level can be obtained directly on commercially available instrumentation which meet accepted performance standards, thus making the screening of toy guns in the field practical.

The specifications for the test site and the measurement locations were chosen to ensure that the measurements would be conducted in a free field. An acoustically free field is an environment without any sound reflecting obstacles. When operated under these conditions, a device will radiate free progressive sound waves. However, perfect free field conditions are not always possible to obtain in practice. Nearly ideal free field conditions can be obtained in an anechoic chamber, and a practical approximation to the acoustically free field is to mount the sound source over a non-reflecting surface above which no disturbing sound reflecting obstacles are present (e.g., outdoors). The measurements are carried out by determining the sound level at various prescribed locations near the gun. A minimum of five points are chosen and these constitute the measurement positions (with the exception of the device for testing paper caps, where it was determined[2] that one measurement position is sufficient). For an example of such a test configuration, see Figure 3. 


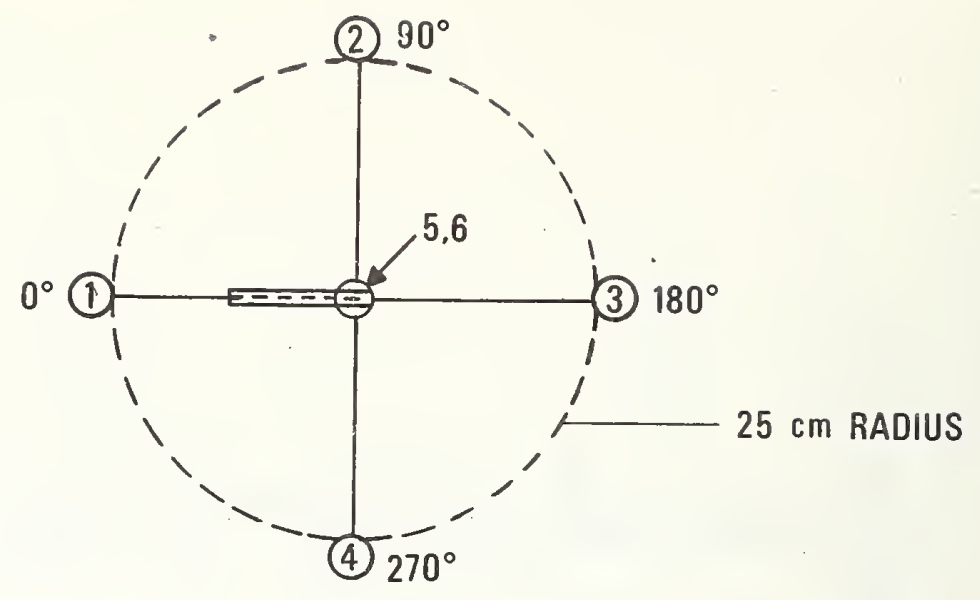

TOP VIEW

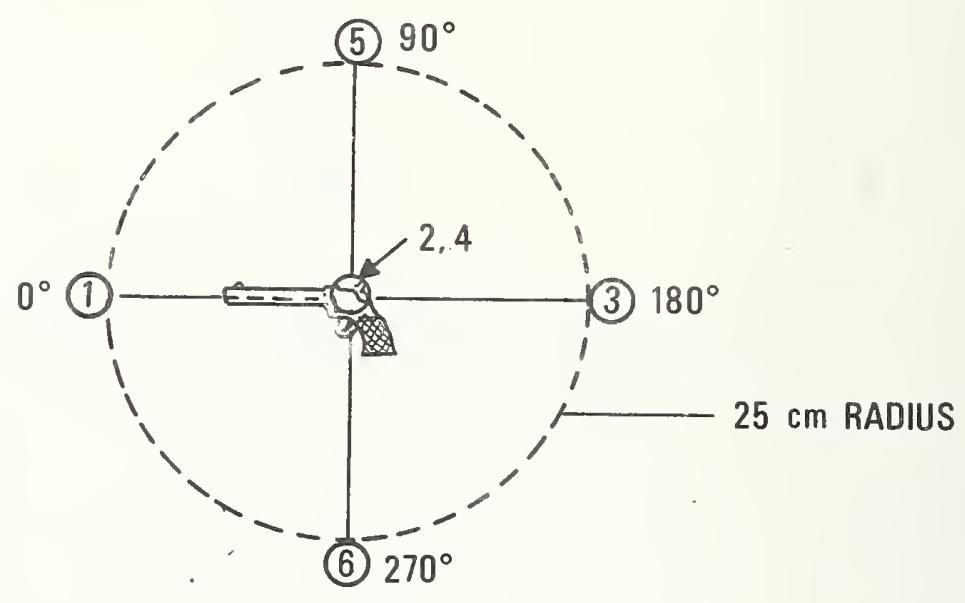

SIDE VIEW

Figure 3. Test configuration for determining the maximum sound pressure level of toy cap pistols. All positions were $25 \pm 1.0 \mathrm{~cm}$ from the point of explosion. Positions 1-4 were on a horizontal plane through the cap pistol barrel. Position 5 was directly above the point of explosion and position 6 was directly below it, and both positions were on a vertical plane through the cap pistol barrel.

\section{Regulation}

\subsection{Measurements Made at Operator Location}

4.1.1. Guns which exceed a peak sound pressure level of $\mathrm{X}$ decibels re: 20 micropascals and/ or an A-weighted sound level of $\mathrm{Z}$ decibels re: 20 micropascals are banned from the market.

4.1.2. Guns which produce peak sound pressure levels in the range $W-X$ decibels and/or A-weighted sound levels in the range $Y-Z$ decibels must bear a visible warning label, and the manufacturer must conduct or participate in a program to develop guns that produce a peak sound pressure level of $\mathrm{W}$ decibels or less, and an A-weighted sound level of $Y$ decibels or less. Also, manufacturers with products in this category must submit regular reports to the Consumer Product Safety Commission on the status of this program. 
4.1.3. Guns which produce peak sound pressure levels less than W decibels and A-weighted sound levels less than $Y$ decibels are allowable on the market with no restrictions.

\subsection{Measurements Made at Positions on Test Envelope Other Than Those at the Operator Location}

4.2.1. Guns which exceed a peak sound pressure level of Q decibels re: $20 \mathrm{micropascals}$ and/or an A-weighted sound level of $\mathrm{S}$ decibels re: $2 \dot{0}$ micropascals are banned from the market.

4.2.2. Guns which produce peak sound pressure levels in the range $\mathrm{P}-\mathrm{Q}$ decibels and/or A-weighted sound levels in the range R-S decibels must bear a visible warning label, and the manufactürer must conduct or participate in a program to develop guns which produce a peak sound pressure level of $\mathrm{P}$ decibels or less, and an A-weighted sound level of $\mathrm{R}$ decibels or less. Also, manufacturers with products in this category must submit regular reports to the Consumer Product Safety Comission on the status of this program.

4.2.3. Guns which produce peak sound pressure levels less than P decibels and A-weighted sound levels less than $R$ decibels are allowable on the market with no restrictions.

\section{Acoustic Environment}

\subsection{Test Site}

The test site shall meet the following specifications: the sound source shall be mounted at least 2 metres \pm 0.1 metre above a surface in an environment where no other sound reflecting obstacles are present within 5 metres of either the location of the gun or the microphone.

\subsection{Measurement Location}

5.2.1. This applies to tests where toy cap pistols and caps are tested as a system.

The microphone shall be located on the same horizontal plane as the gun and $25 \pm 1.0 \mathrm{~cm}$ from the toy gun at all measurement locations. Locate the microphone at measurement positions $1-5$ as shown in Figure 4.

5.2.2. This applied to tests conducted on toy rifles.

The microphone diaphragm shall be located on the same horizontal plane as the gun and $25 \pm 1.0 \mathrm{~cm}$ from the toy gun at all measurement locations (unless specifically noted in Figure 4). Locate the microphone at measurement positions $1-6$ as shown in Figure 4. If the sound source of the gun is located in the stock or along the barrel between the muzzle and the trigger, then four additional measurement positions (corresponding to positions 2-5) shall be designated around the source. (See hypothetical positions 7-10 in Figure 4 for a gun with the sound source in the stock.)

5.2.3. This applies only to measurements made using the standard device for determining the sound level of paper caps (see Section 6.1.1.c. for a description of the device).

The microphone diaphragm shall be in the same horizontal plane as the standard device. Locate the microphone in line with the opening of the anvil with a distance of $25 \pm 1.0 \mathrm{~cm}$ between the diaphragm of the microphone and the point of explosion, as shown in Figure 5 . 

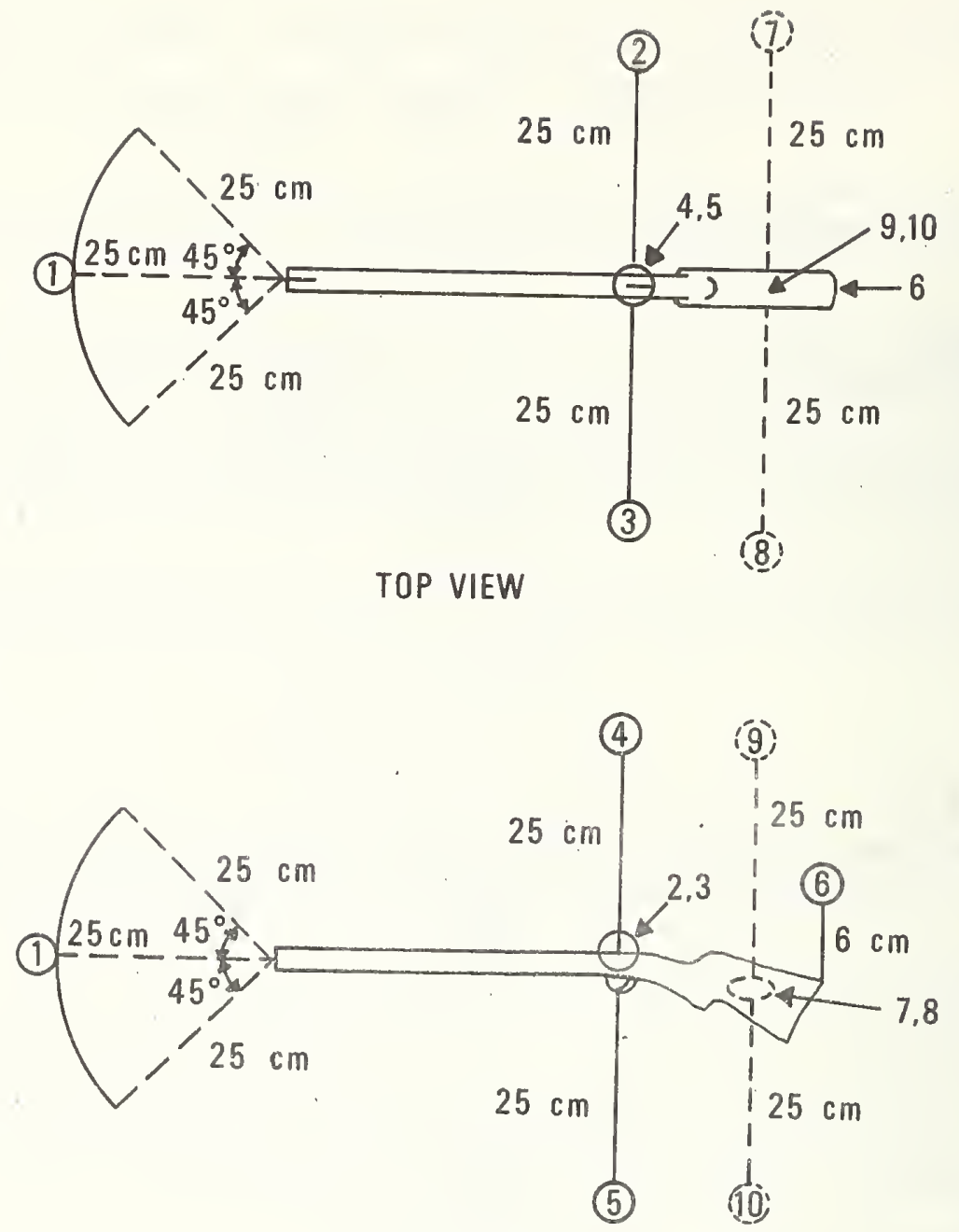

\section{SIDE VIEW}

Figure 4. Test configuration for determining the maximum sound levels of toy guns. All positions are $25 \pm 1.0 \mathrm{~cm}$, unless noted, from the point of explosion. Position 1 is on a horizontal plane through the barrel, and the microphone may be located anywhere on the hypothetical surface depicted (a position directly in front of the muzzle is preferable unless there is a danger that the microphone may be damaged). Positions 2 and 3 are on a horizontal plane through the barrel. Posttion 4 is directly above the trigger and position 5 is directly below it, and both positions are on a vertical plane through the barrel. Posttion 6 is $6 \mathrm{~cm} \pm 0.5 \mathrm{~cm}$ directly above the gun butt plate and on a vertical plane through the butt plate. Positions 7-10 are hypothetical, for a sound source in the stock, and correspond to positions $2-5$, respectively. 

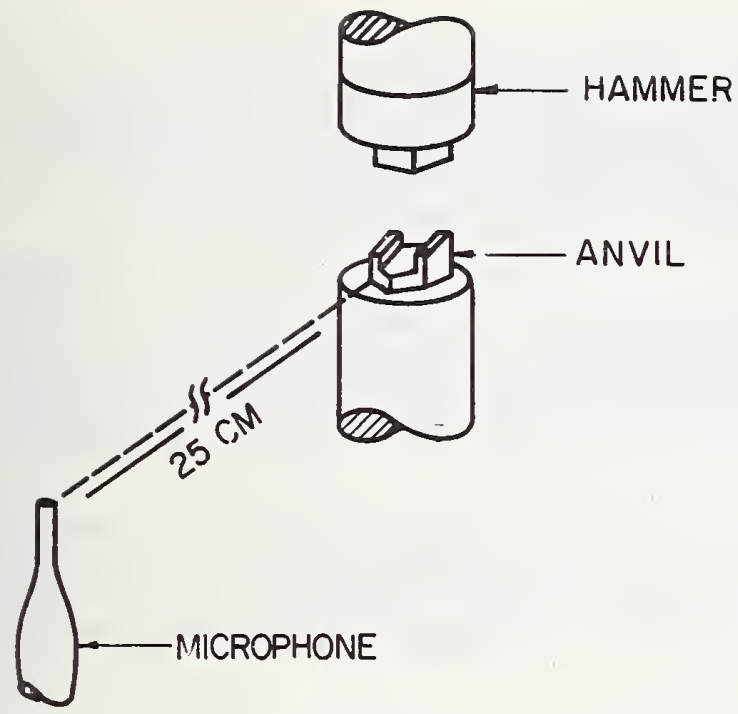

Figure 5. Test configuration for determining the maximum sound levels of paper caps. The microphone diaphragm is $25+1.0 \mathrm{~cm}$ from the point of explosion, and in the same horizontal plane as the standard firing apparatus.

\subsection{Environmental Conditions}

5.3.1. If calibration devices are utilized which are not independent of ambient pressure (e.g., a pistonphone) corrections must be made for barometric or altimetric changes according to the recommendations of the instrument manufacturer.

5.3.2. When measurements are made out-ofdoors, the following conditions must be met.

5.3.2.a. Measurements shall not be made when the wind speed exceeds 5 metres/second.

5.3.2.b. Measurements shall not be made during precipitation.

\subsection{Background Noise}

The background noise shall be such that it shall not affect the measurement results by more than $0.5 \mathrm{~dB}$.

\section{Measurement Methodology}

\subsection{Instrumentation}

6.1.1. The following instrumentation shall be used to determine the impulse noise emission levels of a toy gun.

6.1.1.a. Microphone-Preamplifier System: The microphone-preamplifier system shall have the following characteristics. It shall have a free-field response uniform to within \pm 2 decibels from 50 hertz to 70 kilohertz or beyond and a dynamic range covering the interval 70 to 160 decibels relative to 20 micropascals. The microphone diaphragm shall be used at normal or at grazing incidence to the sound, whichever gives the most uniform free-field response.

6.1.1.b. Oscilloscope: The oscilloscope shall be the storage type or one equipped with a camera. It shall have a response uniform to within \pm 1 decibel from 50 hertz to 250 kilohertz or higher. It shall be calibrated to within \pm 1 decibel against an external voltage source periodically during the tests.

6.1.1.c. Special Equipment: For testing paper caps, a device meeting the following specifications shall be used to explode the caps.

The standard cap gun shall consist of a hammer which strikes the cap, an anvil in which the cap is placed, and a mechanism by which the hammer may be dropped from a fixed height so as to accurately strike the cap in the anvil. Specifically, the cap gun shall meet the following specifications: 
1. The steel hammer shall be $0.95 \pm .05 \mathrm{~cm}$ square and at least $0.6 \mathrm{~cm}$ thick. The bottom of the hammer (1.e., the face which strikes the cap) shall be convex, with a $2.5 \pm 0.5 \mathrm{~cm}$ radius of curvature. The hammer shall be rigidly attached to the center of the bottom of a metal weight such that the combined mass of the hammer and weight is $1.25 \pm .10 \mathrm{~kg}$. In order not to impede propagation of sound waves, no lateral dimension of the weight shall exceed $2.6 \mathrm{~cm}$.

2. The steel anvil shall be of the following general configuration. The recessed portion in which the cap is placed shall be $1.1 \mathrm{~cm}$ wide so that the hammer, when dropped, will consistently strike the bottom of the receptacle squarely without touching the sides. The anvil shall be rigidly attached to a rigid pedestal which is at least $20 \mathrm{~cm}$ high with no lateral dimension exceeding $2.6{ }^{\circ}$ $\mathrm{cm}$. The pedestal in turn shall be rigidly affixed to a massive, rigid base.

3. The mechanism which is used to drop the hammer shall be such as to ensure that the hammer drops squarely, without rotating, into the receptacle in the anvil. The mechanism shall be such as to ensure that the hammer drops $3.5 \pm 0.5 \mathrm{~cm}$. before striking the anvil. An example of a device meeting the above specifications is depicted in Appendix B.

\subsection{1.e. Additional Instrumentation Requirements}

1. An anemometer or other device for measurement of ambient wind speed accurate within $\pm 10 \%$ at $5 \mathrm{~m} / \mathrm{sec}$.

2. A thermometer for measurement of ambient temperature accurate within $\pm 1^{\circ} \mathrm{C}$.

3. A barometer for measurement of ambient pressure accurate within $\pm 1 \%$.

6.1.2. The following instrumentation shall be used to determine the continuous noise emission levels of a toy gun.

6.1.2.a. Microphone: The microphone shall have the following characteristics. It shall be a one-half inch microphone or smaller, and shall have a dynamic range covering the interval 70 to $n$ decibels relative to 20 micropascals, where $\mathrm{n}$ decibels is $10 \mathrm{~dB}$ greater than $\mathrm{S}$ or $\mathrm{Z} \mathrm{dB}$.

6.1.2.b. Sound Level Meter: The sound level meter, including the microphone, shall meet, at a minimum, the specifications of a Type 1 meter as given in American National Standard Specification for Sound Level Meters, S1.4-1971[8], and the provisions of International Electrotechnical Commission Recommendation for Precision Sound Level Meters, Publication 179[9]. The microphone diaphragm on the sound level meter shall be used at normal or at grazing inciderce to the sound, whichever gives the most uniform free-field response.

6.1.2.c. Special Equipment: None required.

\subsection{2.d. Additional Instrumentation Requirements}

1. An anemometer or other device for measurement of ambient wind speed accurate within $\pm 10 \%$ at $5 \mathrm{~m} / \mathrm{sec}$.

2. A thermometer for measurement of ambient temperature accurate within $\pm 1^{\circ} \mathrm{C}$.

3. A barometer for measurement of ambient pressure accurate within $\pm 1 \%$. 


\subsection{Calibration}

The measurement system shall be calibrated both before and after the tests at each microphone position. The calibration shall be accurate to within \pm 1 decibel. If the calibration is of the pressure type or of the pistonphone plus electrostatic actuator type, it shall be corrected to free-field conditions in accordance with the manufacturer's instructions. The calibrator shall be checked annually to verify that its output has not changed.

A complete calibration of the instrumentation over the entire frequency range of interest shall be performed at least annually using methodology of sufficient precision and accuracy to determine that the insirumentation is in compliance with the requirements of Sections 6.1.1 and 6.I.2.

\subsection{Operation of Toy Gun}

The toy gun under test shall be operated in two modes. They are:

(1) Single shot: to obtain a reading of impulse noise emission.

(2) Fired continuously as fast as possible: to obtain a reading of continuous noise emission.

\subsection{Measurements}

\subsubsection{Impulse Noise Emission Test}

6.4.1.1. The quantity to be measured, under the test conditions described in Section 6.3.1, is the peak voltage for each shot as defined by the CHABA impulse-noise damage-risk criterion[5].

6.4.1.2. A minimum of ten shots shall be fired at each measurement location. Obtain readings on the oscilloscope of the maximum peak voltages. Arithmetically average the peak voltages for each of the measurement locations.

6.4.1.3. Convert the average peak voltage value for each measurement location to sound pressure level in decibels relative to 20 micropascals using the response to the calibrated measuring system.

6.4.1.4. The highest average sound pressure level recorded during these test.s shall be utilized to determine compliance with the regulation.

6.4.1.5. The wind velocity, barometric pressure, and ambient temperature shall be measured at the microphone height and within at least 3 metres of of the microphone location.

\subsubsection{Continuous Noise Emission Test}

6.4.2.1. The quantity to be measured, under the test conditions described in Section 6.3.2, is the A-weighted sound level for slow meter response as defined in American National Standard S1.4-1971[8].

6.4.2.2. A minimum of five firings shall be made at each measurement location. Fire the gun for a period of five seconds, and then record the highest reading observed on the sound level meter as the gun is being fired. Average the results of the five firings for each measurement location.

6.4.2.3. The highest average sound level recorded during these tests shall be utilized to determine compliance with the regulation.

6.4.2.4. The wind velocity, barometric pressure, and ambient temperature shall be measured at the microphone height and within at least 3 metres of the microphone location. 


\subsection{Data to be Recorded \\ 6.5.1. General Information}

The following information shall be recorded for all tests:

1. Complete identification and description of the test equipment (In addition, a calibration history of all equipment utilized shall be malntained).

2. Complete identification of sound source under test.

3. Mounting and operating conditions of sound source.

4. Location of sound source in test area.

5. Description of test area.

6. Description of test conditions, including ambient temperature $\left({ }^{\circ} \mathrm{C}\right)$, ambient wind speed during measurements $(\mathrm{m} / \mathrm{sec})$, and atmospheric pressure (mm Hg).

7. Complete description of deviations, if any, from the prescribed test procedure.

8. Number of measurements made during test.

9. Positions at which measurements were made.

10. Date and time when the measurements were performed.

\subsubsection{Impulse Noise Emission Test}

The following information shall be recorded when the impulse noise emission test is conducted:

1. The average peak sound pressure level shall be recorded at each measurement location during the tests.

2. The range of recorded sound pressure levels shall be reported.

\subsubsection{Continuous Noise Emission Test}

The following information shall be recorded when the continuous noise emission test is conducted:

1. The average A-weighted sound level, using the slow response characteristic of the sound level meter, shall be recorded at each measurement location during the tests.

2. The range of the recorded A-weighted sound levels shall be reported. 


\section{References}

[1] U. S. Federal Register, Method for determining the sound pressure level produced by toy caps, 36, No. 134, Section 191.17, 13030 (July 13, 1971).

[2] Cadoff, M. A., Mathews, D. E., and Blomquist, D. S., Development of a procedure for measuring the noise of paper caps, NBS Technical Note 793. (National Bureau of Standards, Washington, D. C., October 1973).

[3] American National Standard Methods for the Measurement of Sound Pressure Levels, S1.13-1971 (American National Standards Institute, New York, New York, July 14, 1971 ).

[4] Information on levels of environmental noise requisite to protect public health and welfare with an adequate margin of safety, Report No. EPA 550/9-74-004 (U. S. Environmental Protection Agency, Washington, D. C., March 1974).

[5] Ward, W. D., et al, Proposed damage risk criterion for impulse noise (gunfire), Report of Working Group 57, NAS-NRC Committee on Hearing, Bioacoustics, and Biomechanics (CHABA) (National Academy of Sciences, Washington, D. C., July 1957).

[6] U. S. Federal Register, Exemptions from classification as a banned toy, 36, No. 134, Section 191.65a, 13030 (July 13, 1971).

[7] Peterson, A. P. G., and Gross, E. E., Jr., Handbook of Noise Measurement (Genera1 Radio Co., Concord, Massachusetts, 1972).

[8] American National Standard Specification for Sound Level Meters, S1.4-1971 (American National Standards Institute, New York, New York, Apri1 27, 1971).

[9] International Electrotechnical Commission Recommendation for Precision Sound Leve1 Meters, Publication 179 (Internationa1 Electrotechnical Commission, Geneva, Switzerland, 1965). 


\section{APPENDIX A}

191.17. Method for Determining the Sound Pressure Level Produced by Toy Caps.

(From: Federal Register 36, No. 134, p. 13030, Ju1y 13, 1971)

"(a) Equipment Required. The equipment for the test includes a microphone, a preamplifier (if required), and an oscilloscope.

(1) The microphone-preamplifier system shall have a free-fleld response uniform to within +2 decibels from 50 hertz to $70 \mathrm{kllohertz}$ or beyond and a dynamic range covering the interval 70 to 160 decibels relative to 20 micronewtons per square meter. Depending on the model, the microphone shall be used at normal or at grazing incldence, whichever gives the most uniform free-field response. The microphone shall be calibrated both before and after the test of a model of cap. The calibration shall be accurate to within \pm 1 decibel. If the calibration is of the pressure type or of the pistonphone plus electrostatic actuator type, it shall be corrected to free-field conditions in accordance with the manufacturer's instruction.

(2) The oscilloscope shall be the storage type or one equipped with a camera. It shall have a response uniform to within \pm 1 decibel from 50 hertz to 250 kilohertz or higher. It shall be calibrated to within +1 decibel against an external voltage source periodically during the tests.

(b) Procedure.

(1) Use the type pistol that would ordinarlly be used with the caps being tested. Place the pistol and testing equipment so that neither the pistol nor the microphone is closer than 1 meter from any wall, floor, ceiling, or other large obstruction. Locate the pistol and the microphone in the same horizontal plane with a distance of 25 centimeters between the diaphragm of the microphone and the position of the explosive. Measure the peak sound pressure level at each of the six designated orientations of the pistol with respect to the measuring microphone. The $0^{\circ}$ orientation corresponds to the muzzle of the pistol pointing at the microphone. The $90^{\circ}, 180^{\circ}$, and $270^{\circ}$ orlentations are measured in a clockwise direction when looking down on the pistol with its barrel horizontal, as illustrated by the following figure.

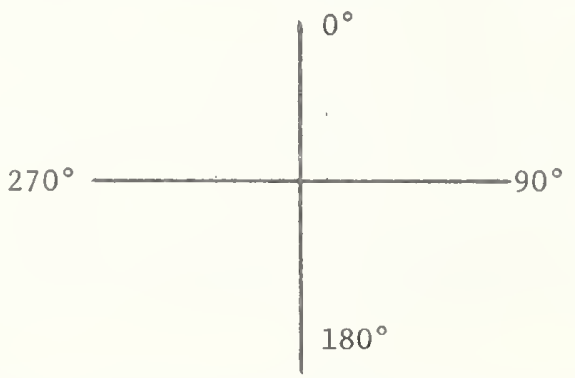

(2) The hammer and trigger orientations are obtained by rotating the pistol about the axis of the barrel, when the pistol is in the $90^{\circ}$ or $270^{\circ}$ orientation, so that the hammer and the trigger are each respectively closest to and in the same horizontal plane with the microphone.

(3) Fire 10 shots at each of the six orientations, obtaining readings on the oscilloscope of the maximum peak voltage for each shot. Average the results of the 10 firings for each of the six orientations.

(4) Using the orientation that yields the highest average value, convert the value to sound pressure levels in decibels relative to 20 micronewtons per square meter using the response to the calibrated measuring microphone." 
APPENDIX B

Assembly Drawing of a Standard Cap Gun [2].

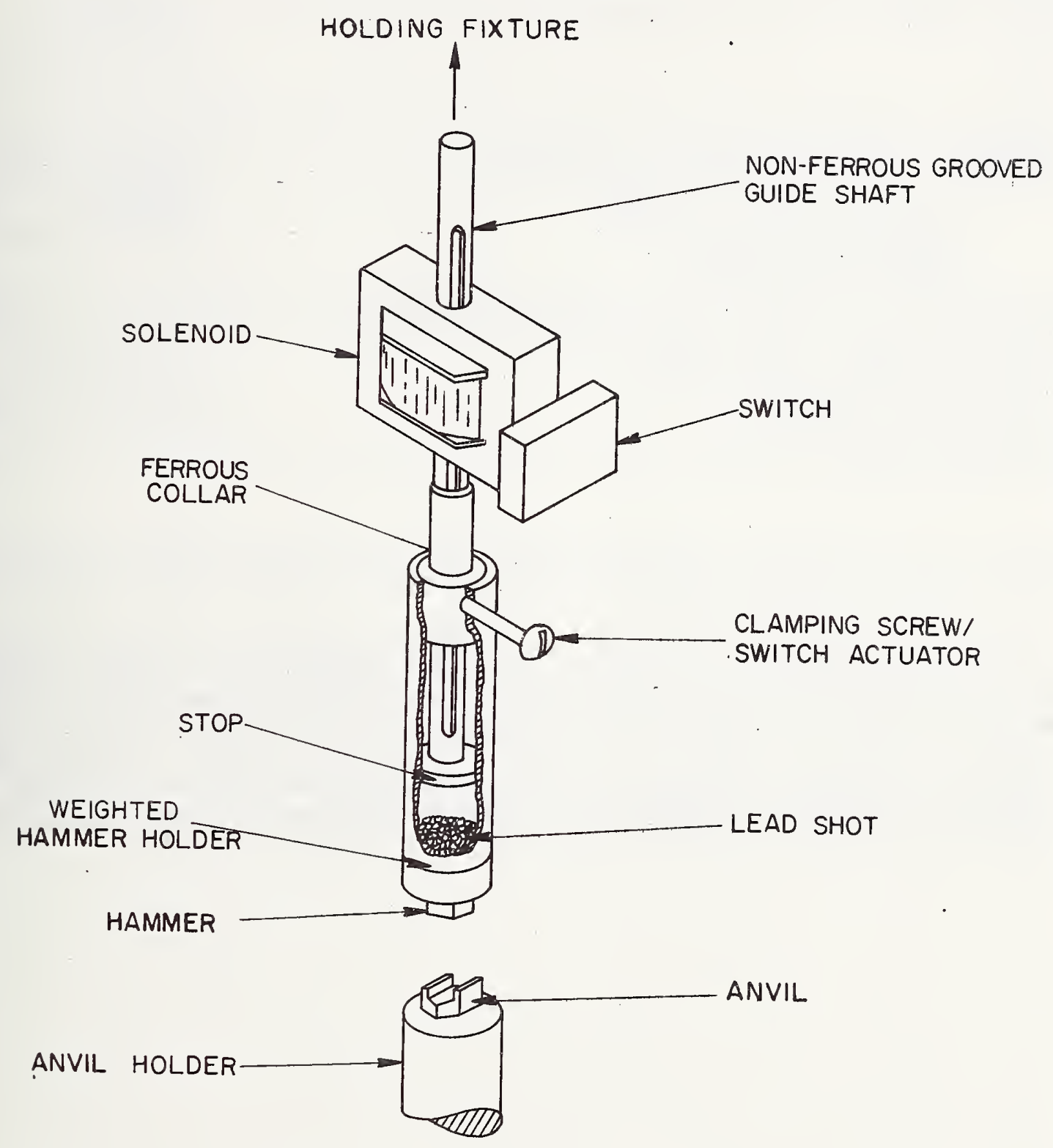


NBS. IIAA \{KEV, 7.73)

\begin{tabular}{|c|c|c|c|}
\hline $\begin{array}{l}\text { U.S. OEFT, OF COMM. } \\
\text { BIBLIOCRAFIIC DATA } \\
\text { SHERP }\end{array}$ & $\begin{array}{l}\text { 1. PUIBIC ATION OK RIPORT NO, } \\
\text { NBSIR } 74=619\end{array}$ & $\begin{array}{l}\text { 2. Gov't Aecession } \\
\text { No. }\end{array}$ & 3. Recipient's Aceession No. \\
\hline \multirow{2}{*}{\multicolumn{3}{|c|}{ 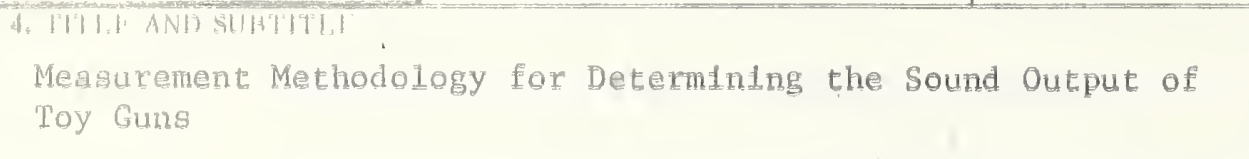 }} & \multirow{2}{*}{$\begin{array}{l}\text { 5. Publication Date } \\
\text { Augugt } 1974 \\
\text { 6. Performing Organization Code }\end{array}$} \\
\hline & & & \\
\hline \multicolumn{3}{|c|}{$\begin{array}{l}\text { 7. AUThOR(S) } \\
\text { Marilyn A. Cadoff and Donald S. Blomquist }\end{array}$} & $\begin{array}{l}\text { 8. Performing Organ. Report No. } \\
\text { NBSIR 74-619 }\end{array}$ \\
\hline \multirow{2}{*}{\multicolumn{3}{|c|}{$\begin{array}{l}\text { 9. PEREORMING ORGANIZATION NAME AND ADDRESS } \\
\qquad \begin{array}{l}\text { NATIONAL BUREAU OF STANDARDS } \\
\text { DEPARTMENT OF COMMERCE } \\
\text { WASHINGTON, D.C. } 20234\end{array}\end{array}$}} & $\begin{array}{l}\text { 10. Project/Task/Work Unit No. } \\
2130496\end{array}$ \\
\hline & & & 11. Contract/Grant No. \\
\hline \multirow{2}{*}{\multicolumn{3}{|c|}{$\begin{array}{l}\text { 12. Sponsoring Organization Name and Complete Address (Street, City, State, ZIP) } \\
\text { Consumer Product Safety Commission } \\
\text { Bureau of Engineering Sciences } \\
5401 \text { Westbard Avenue } \\
\text { Bethesda, Maryland } 20014\end{array}$}} & $\begin{array}{l}\text { 13. Type of Report \& Period } \\
\text { Covered Final } \\
7 / 1 / 73-6 / 30 / 74\end{array}$ \\
\hline & & & 14. Sponsoring Agency Code \\
\hline
\end{tabular}

15. SUPPLEMENTARY NOTES

16. ABSTRACT (A 200-word or less factual summary of most significant information. If document includes a significant bibliography or literature survey, mention it here.)

In recent years, a great concern has been expressed for consumer protection and safety, especia1ly for children. As an outgrowth of this concern, acoustical testing of potentially-hazard us noise-producing toys has been carried out at the National. Bureau of Standards for the Consumer Product Safety Commission under the authority of the Toy Safety Act of 1969. This report outlines a methodology which was developed to measure the noise levels of toy guns. In addition, the rationale and technical back-up for the methodology are discussed, and the regulations setting allowable noise levels for toy guns are given.

17. KEY WORDS (six to twelve entries; alphabetical order; capitalize only the first letter of the first key word unless a proper name; separated by semicolons)

Children; consumer safety; guns; hearing damage; noise; standard apparatus; toys.

18. AVAILABILITY Unlimited

For Official Distribution. Do Not Release to NTIS

Order From Sup. of Doc., U.S. Government Printing Office

Washington, D.C.20402, SD Cat. No.C13

Order From Nacional Technical Information Service (NTIS) Springfield, Virginia 22151

\begin{tabular}{|l|c|}
\hline $\begin{array}{l}\text { 19. SECURITY CLASS } \\
\text { (THIS REPURT) }\end{array}$ & 21. NO. OF PAGES \\
UNCL ASSIFIED & 15 \\
\hline $\begin{array}{l}\text { 20. SECURITY CLASS } \\
\text { (THIS PAGE) } \\
\text { UNCLASSIFIED }\end{array}$ & 22. Price \\
\hline
\end{tabular}





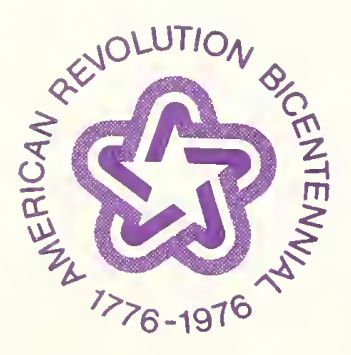




(1MN 
